\title{
Guerrino Pellicia, Giancarlo Rocca (éds.), Dizionario degli Istituti di Perfezione
}

Rome, Edizioni Paoline, 2003, t. 10, XXV+1682 p. (bibliogr., index, annexes)

Jean Séguy

\section{CpenEdition}

Journals

Édition électronique

URL : http://journals.openedition.org/assr/2641

DOI : 10.4000/assr.2641

ISSN : $1777-5825$

Éditeur

Éditions de l'EHESS

Édition imprimée

Date de publication : 1 octobre 2004

Pagination : 53-158

ISBN : 2-222-96754-6

ISSN : 0335-5985

Référence électronique

Jean Séguy, «Guerrino Pellicia, Giancarlo Rocca (éds.), Dizionario degli Istituti di Perfezione », Archives de sciences sociales des religions [En ligne], 128 | octobre - décembre 2004, document 128.79, mis en ligne le 18 novembre 2005, consulté le 24 septembre 2020. URL : http://journals.openedition.org/assr/ 2641 ; DOI : https://doi.org/10.4000/assr.2641 
PELLICIA (Guerrino), ROCCA (Giancarlo), eds.

Dizionario degli Istituti di Perfezione. Rome, Edizioni Paoline, 2003, t. 10, XXV+1682 p. (bibliogr., index, annexes).

Le volume 9, précédent, du DIP datait de 1997 (Arch., 102.106). Quelles que soient les raisons qui ont retardé la parution de ce tome 10 , on peut assurer que les mêmes qualités qui signalent les tomes précédents se retrouvent ici.

Ce dixième volume se compose de deux parties : une partie «dictionnaire»- sur 692 colonnes - prolongeant le tome 9 (entre le mot «Via » jusqu'à l'article « Zwÿsen, Joannes ») ; l'espace entre les colonnes suivantes (col. 693 à col. 1682) est occupé par trois «Appendices »: un complément sur l'histoire générale de la vie religieuse féminine, intitulé «Sanctimoniales » (col. 701 à 784), dû à plusieurs collaboratrices du DIP sous la direction de G.R. Cette entrée vise explicitement à mettre à jour les articles traitant du même sujet dans les volumes précédents et à compléter autant que possible la bibliographie (multilingue) le concernant.

Le deuxième «Appendice » (col. 785 à 888) recueille des statistiques. Les col. 785 à 794 détaillent la façon dont lesdites statistiques ont été réunies, comment et pourquoi il a fallu se contenter en la matière des données fournies par la Congrégation romaine pour les instituts de vie consacrée et les sociétés de vie apostolique, ainsi que par les instituts religieux eux-mêmes ; des informations complémentaires ont aussi été tirées de l'Annuarium Statisticum Ecclesiae et de l'Annuario Pontificio. Pour les Instituts séculiers, les informations rassemblées - pas toutes nécessairement complètes - ont été fournies par la Congrégation pour les religieux et les Instituts séculiers.

Les statistiques rassemblées dans cet Appendice concernent, pour la plupart, des années postérieures au Concile Vatican II (1966, 1972, 1990, 2000). Les éditeurs du DIP auraient aimé pouvoir joindre à cette collecte un certain nombre de statistiques comparables entre elles et avec les précédentes; ce vœu a dû être reconnu irréalisable (on passe ici sur les raisons de cet «échec »).

Le troisième Appendice annoncé plus haut est fait de deux «Index »: «Auteurs » et «Analytique ». À un usage de plusieurs mois, ces instruments nous ont paru fiables et commodes.

Comme l'ensemble des volumes précédents, ce tome 10 contient de nombreux articles longs, écrits par des auteurs multiples et - apparemment - à jour de leur information. Parmi les produits de ce genre susceptibles d'intéresser anthropologues, historiens, sociologues - et même théologiens - on retiendra les «entrées » qui traitent de «Vie active», de «Vie contemplative », du concept de «Vie mixte», de «Vocation », enfin ; ce dernier (col. 476-533) comprend le récit d'une vocation érémitique écrit par l'ermite concerné lui-même.

L'entrée «Vie commune » (col. 270-349) inclut une partie «Aspects sociologiques» traitée successivement par E. Pace (Padoue, col. 340-346) et Burgalassi (Milan et Pise, col. 346-349).

L'article «Vie quotidienne » (col. 366-455) retiendra l'attention des historiens des mentalités intéressés par l'existence concrète des religieuses françaises du XVII ${ }^{\mathrm{e}}$ siècle (J. Lebrun, Paris, col. 429-432) et par le « rapport au corps » chez les religieuses également françaises mais du XIX ${ }^{\mathrm{e}}$ siècle $(\mathrm{O}$. Arnold, Paris, col. 433-442) ; les problèmes du réfectoire dans divers groupes et à diverses époques se trouvent étudiés par G.R. (Rome) entre les col. 442-450. Enfin, toujours sous la même rubrique «Vie quotidienne », E. Pace (Padoue) aborde (col. 450455) quelques questions de théorie sociologique autour du concept de « vie quotidienne » appréhendé à partir de divers sociologues contemporains.

Trois articles méritent encore signalement : celui, très informé, de Valdo Vinay traitant des «Veilleurs» («Vigilanti », col. 48-49). Cet original groupe de vie spirituelle dont les membres vivent dispersés en lieux et occupations profanes et pastorales diverses admet dans ses rangs des membres issus de la variété assumée des Églises et des groupes de terrain protestant. Les Veilleurs vivent principalement en France et en Suisse ; ils ne possèdent pas d'œuvres communes; ils ont par contre des pratiques de piété communes et se réunissent localement ou autrement à dates fixes. Ils se considèrent comme un Tiers-Ordre protestant (qui n'aurait cependant ni premier ni second ordre qui le soutiennent et le légitiment).

L'article «Voillaume, René » (col. 434435), dû à la plume de I. Lustrissimi (Ostie) déçoit: on y verra, au mieux, une nécrologie rapide. Le fondateur des Petites Sœurs et des Petits Frères de Jésus, puis des Petits Frères et des Petites Sœurs de l'Évangile méritait mieux que ce court article pressé ! Le rôle de ce prêtre et de ses fondations dans le prolongement de l'héritage du P. de Foucauld, spirituel notoire dont les ouvrages et l'activité ont induit des transformations notables dans de nombreux milieux catholiques entre la dernière guerre 
mondiale et les débuts du XXI ${ }^{\mathrm{e}}$ siècle, aurait pu et dû être relevé et commenté plus amplement.

Enfin, l'article «Voltaire et voltairianisme » (col. 541-546) par B. Peyrous - prêtre du diocèse de Bordeaux - est d'un historien connaissant le courant antimonastique des Lumières.

Jean Séguy.

128.80

PÉROUAS (Louis), LAGUIONIE (Michel), MARIGLIER (Roger).

Franc-Maçonnerie et antimaçonnisme en Limousin, amorces d'un dialogue. Limoges, Presses universitaires de Limoges, 2002, 82 p., (préface de Jean Baubérot).

Cette forte plaquette rassemble plusieurs études conçues dans des perspectives très différentes, ce qui n'enlève rien à leurs qualités et contribue à exorciser la peur qui est « mauvaise conseillère », comme le note Jean Baubérot dans sa préface, pour l'établissement d'un dialogue. M.L., historien et membre du Grand Orient de France dresse, après une présentation générale « engagée » de l'institution, un tableau historique de la maçonnerie en Limousin suivi d'un très intéressant état des lieux actuel par obédience (toutes sont présentes mais le Grand Orient reste prédominant malgré un grand effort d'implantation de la Grande Loge Nationale française). L.P., historien et prêtre catholique, analyse ensuite les prises de position et l'évolution des prêtres locaux au fur et à mesure que se durcit le conflit avec l'Église au XIX ${ }^{\text {e }}$ siècle ; il résume pour finir les tentatives de rapprochement depuis les Pères Berteloot et Riquet couronnées par le colloque de Toulouse de 1987, organisé par Paul Pistre, un ardent partisan du dialogue, sur «Église/Maçonnerie, condamnation ou malentendu ? Deux siècles de conflit ». Un échange entre L.P. et un dignitaire du Grand Orient, R.M., clôt, dans un genre déjà bien « rodé », cette approche très documentée. La brièveté de ce travail interdisait une recherche plus approfondie, cependant quelques affirmations sont surprenantes telle que l'absence d'un antimaçonnisme aux État-Unis (p. 17), l'universalité du symbolisme sans autre explication du point de vue (p. 25) ou l'absence de tout lien avec le phénomène "Rose-Croix » (p. 15). Une coquille malheureuse sur le nom d'un auteur-clef pour le sujet : Ferrer-Benimelli et non Bonimelli.

Jean-Pierre Laurant.
128.81

PHIRI (Isaac).

Proclaiming Political Pluralism. Churches and Political Transitions in Africa. WestportLondres, Praeger, 2001, 169 p. (bibliogr., index) (coll. "Religion in the Age of Transformation »).

C'est l'influence des Églises chrétiennes dans les transitions politiques africaines des années 1990 qui est à l'origine de la réflexion développée par I.P. dans cet ouvrage : il cherche à comprendre les raisons et les modalités de l'émergence des Églises en tant qu'acteurs des transitions vers la démocratie. Après un chapitre introductif dans lequel I.P. précise notamment son cadre d'analyse, trois chapitres sont consacrés à des études de cas portant respectivement sur la Zambie, le Zimbabwe et l'Afrique du Sud. Un dernier chapitre aborde la question du rôle politique que les Églises devraient jouer dans le contexte actuel.

L'auteur émet l'hypothèse que les Églises interviennent d'autant plus dans les arènes politiques africaines que les pouvoirs autoritaires ont, par la répression, contraint au silence les forces politiques et sociales susceptibles de s'opposer à lui. Les Églises apparaissent alors comme les seules composantes de la société civile aptes à résister : face au vide créé par l'État autoritaire, elles remplissent ainsi un rôle politique. Ce cadre d'analyse s'appuie essentiellement sur un article de Jean-François Bayart, publié en 1973 dans la Revue française de Science politique (vol. XXIII, no 3, pp. 514-536), portant sur la fonction politique des Églises au Cameroun. Trois modèles de relation entre Églises et État sont proposés, liés au degré de répression qui affecte la société civile : la collaboration, la coexistence ou le conflit. Dans ce dernier cas, les Églises remplissent une fonction dévolue aux groupes d'opposition.

Dans les chapitres portant sur des études de cas, I.P. essaie d'appliquer ce modèle aux trois pays qu'il étudie. Pour la Zambie et le Zimbabwe, il propose, après une présentation des forces religieuses en présence, une approche historique des relations entre l'État et les Églises, depuis l'époque coloniale jusqu'aux changements politiques des années 1990. Des personnalités émergent, comme Frederick Chiluba, cet ancien leader syndicaliste, converti au christianisme évangélique en prison. Élu président de la République en 1991, il proclame la Zambie «nation chrétienne », d'ailleurs au grand dam de certaines Églises. Le cas sud-africain permet surtout à l'A. de souligner les relations différenciées des Églises avec l'État: collaboration et soutien à l'apartheid pour la Dutch Reformed Church, implication politique 